\title{
Correction to: Heat Shock Protein 90 Stimulates Rat Mesenchymal Stem Cell Migration via PI3K/Akt and ERK1/2 Pathways
}

\author{
Feng Gao ${ }^{1,2,3} \cdot$ Xinyang $\mathrm{Hu}^{1,2} \cdot$ Xiaojie Xie $^{1,2} \cdot \mathrm{Xianbao}^{\mathrm{Li}}{ }^{1,2} \cdot$ Jianan Wang ${ }^{1,2}$
}

Published online: 15 June 2019

(C) Springer Science+Business Media, LLC, part of Springer Nature 2019

Correction to: Cell Biochem Biophys (2015) 71:481-489
https://doi.org/10.1007/s12013-014-0228-6

Unfortunately, the original version of this article contains mistakes in Fig. 7a, b. The bands for the internal controls have been inadvertently repeatedly used in Fig. 7a, b. The authors regret the oversight, and the correct figure is presented in this correction.

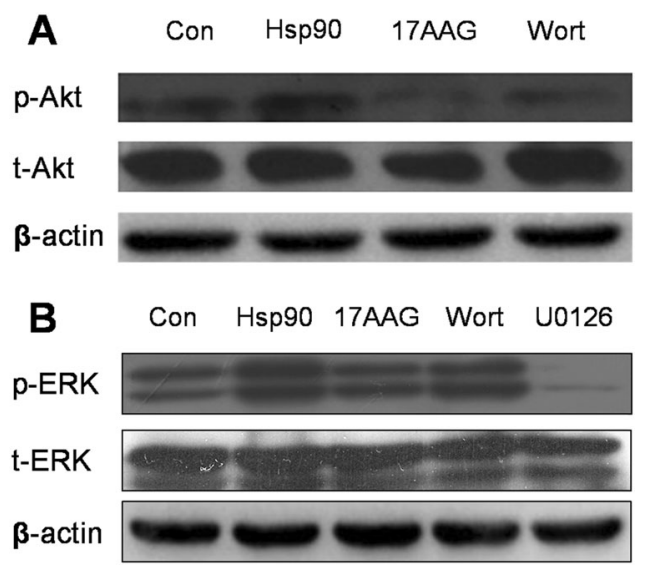

Fig. 7 The effect of rhHsp90 $\alpha$ on PI3K/Akt and ERK pathways in MSC. MSC were pre-treated with 17-AAG, wortmannin, and U0126 when required, and incubated with rhHsp $\alpha$ for $24 \mathrm{~h}$. Levels of p-Akt $\mathbf{a}$ and $\mathrm{p}$-ERK1/2 $\mathbf{b}$ were measured by Western blotting and normalized for total Akt and ERK1/2, respectively. $\beta$-Actin was used as a loading control
The original article can be found online at https://doi.org/10.1007/ s12013-014-0228-6.

Jianan Wang

jiananwang2014@163.com

1 Department of Cardiology, Second Affiliated Hospital, Zhejiang University College of Medicine, Hangzhou 310009, People's Republic of China

2 Cardiovascular Key Laboratory of Zhejiang Province, Second Affiliated Hospital, Zhejiang University College of Medicine, Hangzhou 310009, People's Republic of China

3 Department of Cardiology, Zhejiang Provincial People's Hospital, Hangzhou 310014, People's Republic of China 